\title{
Climate Policy
}

\section{polsc}

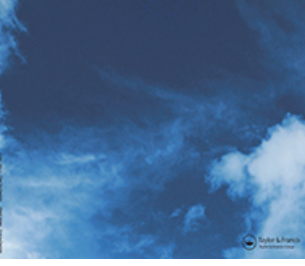

\section{Identifying climate services needs for national planning: insights from Malawi}

\section{Katharine Vincent, Andrew J. Dougill, Jami L. Dixon, Lindsay C. Stringer \& Tracy Cull}

To cite this article: Katharine Vincent, Andrew J. Dougill, Jami L. Dixon, Lindsay C. Stringer \& Tracy Cull (2017) Identifying climate services needs for national planning: insights from Malawi, Climate Policy, 17:2, 189-202, DOI: 10.1080/14693062.2015.1075374

To link to this article: http://dx.doi.org/10.1080/14693062.2015.1075374

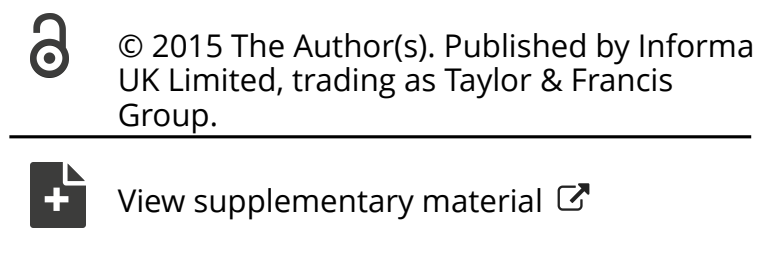

曲 Published online: 20 Aug 2015.

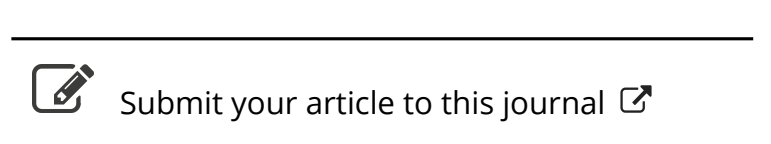

Џlll Article views: 1004

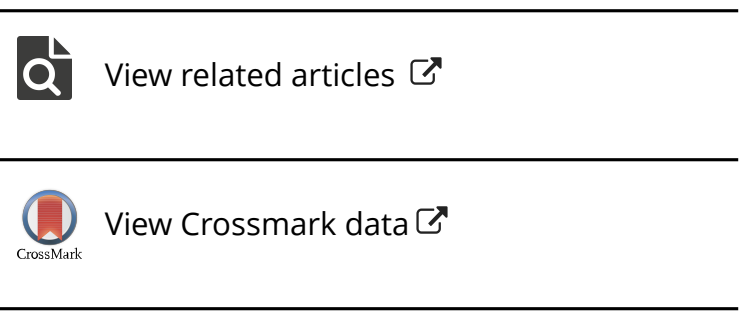




\title{
Identifying climate services needs for national planning: insights from Malawi
}

\author{
KATHARINE VINCENT ${ }^{1,3}$, ANDREW J. DOUGILL ${ }^{2}$, JAMI L. DIXON $^{2 *}$, LINDSAY C. STRINGER ${ }^{2}$, TRACY CULL $^{1}$ \\ ${ }^{1}$ Kulima Integrated Development Solutions (Pty) Ltd, Postnet Suite H79, Private Bag x9118, Pietermaritzburg, 3200, South Africa \\ ${ }^{2}$ School of Earth and Environment, University of Leeds, Leeds LS2 9JT, UK \\ ${ }^{3}$ School of Architecture and Planning, University of the Witwatersrand, Johannesburg, Private Bag 3, WITS 2050, South Africa
}

The importance of climate services, i.e. providing targeted, tailored, and timely weather and climate information, has gained momentum, but requires improved understanding of user needs. This article identifies the opportunities and barriers to the use of climate services for planning in Malawi, to identify the types of information that can better inform future adaptation decisions in sub-Saharan Africa. From policy analysis, stakeholder interviews, and a national workshop utilizing serious games, it is determined that only 5-10 day and seasonal forecasts are currently being used in government decision making. Impediments to greater integration of climate services include spatial and temporal scale, accessibility, timing, credibility and the mismatch in timeframes between planning cycles (1-5 years) and climate projections (over 20 years). Information that could more usefully inform planning decisions includes rainfall distribution within a season, forecasts with 2-3 week lead times, likely timing and location of extreme events in the short term (1-5 years), and projections (e.g. rainfall and temperature change) in the medium term (6-20 years). Development of a national set of scenarios would also make climate information more accessible to decision makers, and capacity building around such scenarios would enable its improved use in short- to medium-term planning. Improved climate science and its integration with impact models offer exciting opportunities for integrated climate-resilient planning across sub-Saharan Africa. Accrual of positive impacts requires enhanced national capacity to interpret climate information and implement communication strategies across sectors.

\section{Policy relevance}

For climate services to achieve their goal of improving adaptation decision making, it is necessary to understand the decision making process and how and when various types of weather and climate information can be incorporated. Through a case study of public sector planning in Malawi, this article highlights relevant planning and policy-making processes. The current use of weather and climate information and needs, over various timescales - sub-annual to short term (1-5 years) to medium term (620 years) - is outlined. If climate scientists working with boundary organizations are able to address these issues in a more targeted, sector-facing manner they will improve the uptake of climate services and the likelihood of climate-resilient decisions across sub-Saharan Africa.

Keywords: adaptation; adaptation policy; decision making; science communication; science-policy interface; serious games

\section{Introduction}

Sub-Saharan Africa (SSA) is highlighted as being particularly vulnerable to climate impacts through a combination of exposure and low adaptive capacity (Niang et al., 2014; Simelton et al., 2012). It is a

[ *Corresponding author. E-mail: jami-dixon@Itsi.co.uk 
region where multi-decadal (10-40 year) climate projections are limited, particularly over central and southern Africa (e.g. James, Washington, \& Rowell, 2014). This is due to a combination of factors, such as poor observational records, high levels of interannual and decadal climate variability that are poorly simulated, and a low level of investment in climate science (Kusangaya, Warburton, Archer van Garderen, \& Jewitt, 2014; Shongwe, van Oldenborgh, van den Hurk, de Boer, Coelho, \& van Aalst, 2009; Washington, James, Pearce, Pokam, \& Moufouma-Okia, 2013). There is a pressing need for climate information to inform national-level planning, and policy and decision making across a range of sectors, environments, and socio-political settings (Jones, Roux, Scott, \& Tanner, 2014; Vaughan \& Dessai, 2014), to support future climate-resilient development and to help safeguard promising trends of economic development across the region.

The increasing recognition of the importance of climate information to inform climate-resilient development has led to a growing focus on the notion of 'climate services'. The aim of climate services is 'to provide people and organizations with timely, tailored climate-related knowledge and information that they can use to reduce climate-related losses and enhance benefits, including the protection of lives, livelihoods, and property' (Vaughan \& Dessai, 2014, p. 588). A number of regional and global initiatives have been established with the aim of improving climate services for integration into planning, policy, and practice. These include the Global Framework for Climate Services (GFCS), ClimDev-Africa, and the Integrated African Strategy on Meteorology (weather and climate services of the African Ministerial Conference on Meteorology, or AMCOMET).

Identifying appropriate entry points for targeting climate services in line with national priorities is essential for more effective use of medium-term climate information in decision making (Conway \& Mustelin, 2014). However, there is a lack of empirical studies assessing the use of such information (Rose, 2014), especially in SSA. Barriers to the use of such information impede successful climate change adaptation initiatives and climate-resilient development planning (Eisenack et al., 2014).

This article addresses the climate services needs of decision makers in SSA through a focused study on Malawi. A variety of climate services exist for Malawi, generated by institutions around the world (McSweeney, New, \& Lizcano, 2010; Vincent, Dougill, Mkwambisi, et al., 2014). However, knowledge is lacking on how this existing information is being used and the demand, in terms of type and timeframe $^{1}$. This is necessary to inform the development of climate science that addresses the information needs for climate-resilient national planning.

Three research questions are examined:

1. What climate services do decision makers currently use and what challenges do they face in their use?

2. What weather and climate (hereafter climate) information do Malawi's ministries and departments (hereafter departments) think would be useful to inform their decision making?

3. What is required to increase the use of climate information in decision making?

\section{Methods}

A policy analysis drawing on discourse analysis approaches was undertaken (Lindseth, 2005) in the following national level plans and policy documents: Vision 2020; Malawi Growth and Development 
Strategy II (2011-16); National Climate Change Policy; National Adaptation Programme of Action; Climate Change Investment Plan; National Disaster Risk Management Policy; Agricultural Sector Wide Approach; National Water Policy 2005; National Environmental Policy 2004; and the draft National Social Protection Policy. These plans and policy documents were chosen based on climate change being explicitly mentioned or implicitly critical. The purpose of the systematic analysis was to determine the climate discourses, the extent to which they are uniform across the plans and policies, and to inform the sampling of interviewees within key departments.

Semi-structured interviews were undertaken in May 2014 with senior public sector decision makers in order to (1) interrogate the nature of department decision making processes (including how these address the discourses of climate change in current policies and strategies) and the extent to which weather and climate information is currently utilized, and (2) identify the most appropriate technical-level planning staff to be invited to a national workshop. Due to limited private sector engagement in climate change efforts across the southern Africa region (Kulima Integrated Development Solutions, 2013; Stringer et al., 2014), only public decision makers and representatives from UN agencies, donors, and NGOs were interviewed. Sampling was purposive and a snowball approach was adopted, starting with contacts in the departments from which the analysed policies originated. A total of 21 semi-structured interviews were held: 14 with government staff, three with NGOs, two with representatives from a UN agency, and two with donors (see Supplemental Material 1). The focus was on food security, social protection systems, and disaster risk management, as cross-country sectors identified as having the greatest opportunities for impacts from increased use of climate services (Vincent, Dougill, Dixon, et al., 2014). Interview notes were subject to thematic analysis around existing and potential information needs and current barriers (Boyatzis, 1998). Results from the analysis of interview data also informed the design of a national stakeholder workshop based around role-playing and serious games, designed to reflect Malawi's decision-making processes.

Representatives from seven government departments in five ministries were invited to a 1.5-day workshop in August 2014. The workshop targeted public decision makers, particularly technical staff in departments with responsibility for planning. Ten Malawian decision makers participated in the workshop (see Supplemental Material 1).

The first workshop activity developed a role-playing scenario that was unfamiliar to all the participants, but had close parallels with their daily jobs. The purpose was to give participants the opportunity to think through what climate information would be useful to inform decision making in the roleplaying scenario. This was designed based on two premises: existing climate adaptation planning games (Jones, Ludi, Beautement, Broener, \& Bachofen, 2013) and findings from the semi-structured interviews, which showed that very few departments use climate services in their planning (for details see Supplemental Material 2).

The second workshop activity was based on the 'Paying for Predictions' game (Mendler de Suarez et al., 2012). This involved a simulation that was designed to demonstrate the potential utility of forecast information and projections, while also highlighting levels of (un)certainty (van Pelt, Haasnoot, Arts, Ludwig, Swart, \& Biesbroek, 2015). The game had two aims: to demonstrate the trade-offs between early investment in risk reduction (via longer-term planning) compared to a wait-and-see decision that might risk high costs later, and to examine decision makers' capacity to use information with different levels of (un)certainty (for details see Supplemental Material 3). 
Having undertaken the first two games, participants were given the opportunity to consider the potential uses, opportunities, and limitations of climate information in planning, based on feasible scenarios. Having considered this, they were better placed to reflect on their own experiences of how climate information may inform the decisions they make within their own departments. The final workshop activity involved small groups from multiple sectors identifying, comparing, and contrasting the day-to-day planning decisions made by each participant and their department. Participants were asked to consider what climate information could usefully contribute to more robust planning and decision making in the context of climate change to produce a list of information needs. The emphasis was on what information would ideally be needed for planning, without the constraints of (their perceptions of) the current limits of climate science and information availability.

\section{Results}

This section breaks down the results to answer the first two research questions. The final research question is addressed in the discussion (Section 4). In order to accurately represent the respondents, they are quoted verbatim, with quotations from interviewees and direct statements from the workshop.

\subsection{What climate services do decision makers currently use and what challenges do they face?}

The majority of information currently used is in the form of sub-annual forecasts (i.e. from daily to seasonal). There was no evidence of the use of short- (1-5 years) or medium- (6-20 years) term climate projections in current sectoral decision making in any of the departments where interviews were conducted. This is despite the availability of Malawi-specific projections (McSweeney et al., 2010) and their use in Malawi's National Communications to the United Nations Framework Convention on Climate Change (UNFCCC). An interviewee from the Ministry of Local Government and Rural Development (MLGRD) stated that they only use 'immediate' weather information in their planning, while the Department of Disaster Management Affairs (DoDMA) and departments in the Ministry of Irrigation and Water Development (MoIWD) use 5-10 day forecasts for planning purposes, with daily updates on extreme weather events. A DoDMA interviewee suggested that they 'do not have long-term plans based on long-term climate scenarios due to resource constraints'. A similar statement was made by an interviewee from the MoIWD, who identified a lack of advance projection capability within the Department of Climate Change and Meteorological Services (DCCMS) as a primary restriction in gaining access to medium-term climate change information, despite them recognizing the value of such information for their infrastructure planning with lifetimes of 6-20 year periods.

Evidence suggests that seasonal forecasts (on a timescale of 1-6 months) are being used to inform annual planning in sectors such as water, energy, agriculture, and disaster management. For example, the DoDMA use seasonal forecasts to inform the National Contingency Plan, while several departments within the Ministry of Agriculture and Food Security (MoAFS) use seasonal forecasts. The Department of Land Resources and Conservation, Department of Crop Production (both in MoAFS), and DCCMS coordinate to produce the Agricultural Crop Production Survey, which provides advice for farmers that is communicated through extension services and radio. However, as yet, they only focus on the coming season and do not consider decadal to medium-term projections that 
could usefully inform future agricultural research investments, irrigation and water resource management planning, and training needs for agricultural extension staff.

Interviewees from departments within the MoIWD outlined that 'seasonal forecast information is being used in planning decisions, but as yet longer-term scenarios are not being used to design new long-term investments, such as irrigation projects'. In the absence of climate model-generated projections, the MoIWD uses statistical extrapolations of past observational records (temperature, potential evapo-transpiration rates, and rainfall). Such linear modelling, which is also used by other departments, including the DoDMA, is problematic in that it assumes both robust observational data coverage and that the future will mirror the past, which is unlikely to be the case under projected climate change.

The Department of Economic Planning and Development (DEPD) in the Ministry of Economic Planning and Development looks at cross-sectoral issues to inform national development strategies and plans, but currently does not actively use any climate information, despite a number of its staff members having participated in the main regional climate change training programme (Winter School at University of Cape Town). Other institutions dealing with cross-sectoral challenges such as food security, for example the Malawi Vulnerability Assessment Committee, also only look to the coming season, with decisions based on past observations of comparative years, rather than model projections.

A number of challenges impeding more active incorporation of climate information into decision making emerged during the interviews and the workshop. These were linked to issues of spatial and temporal scale, accessibility and credibility, policy planning cycles, timing and mismatch in timeframes between planning cycles (1-5 years), and climate projections (over 20 years). This section addresses each of these challenges in turn.

Current information is viewed as inappropriate to spatial and temporal scales of decision making. For example, a representative of the Department of Agricultural Extension Services (DAES) stated that the spatial resolution of available information is not suitably downscaled, and that 'this [downscaling] is extremely important in order to ensure that weather and climate information is not generalised over a number of different agricultural zones'. The DoDMA is more concerned with knowing the timing and spatial distribution of extremes, such as heavy rainfall and strong winds, on a sub-annual to short-term timescale, and they attributed the absence of such information to 'the hardware and equipment to which the DCCMS have access'. On a shorter timescale, the skill level of the DCCMS seasonal forecasts is also perceived to be insufficient to cope with increasing variability and uncertainty. This reduces the potential uses of current information and highlights a need for weather and climate data at higher spatial and temporal resolutions.

The accessibility and credibility of information was also highlighted as a challenge. A key issue identified by the DoDMA and a representative from the Ministry of the Elderly and Persons with Disabilities (MoEPWD) is the packaging of information. The scientific terminology used by the DCCMS was not considered to be easily accessible, and there is currently little tailoring of information to the needs of different users. Communications from the DCCMS tend to be at the national level and are intended to then be 'interpreted' for sectoral context prior to use and further dissemination. Interviewees highlighted that information is not packaged in a form that decision makers can use (e.g. scenarios and sectoral implications). Instead, they are provided with data and no analysis of the trends in, or implications of, these data. This packaging affects credibility - interviewees from the MoEPWD did 
not think that the information they receive is adequate, limiting their confidence and willingness to issue early warnings.

While it was recognized that the regional climate science needed to improve, it was often the communication of information and the lack of training of users that led to problems with the credibility of forecasts. These challenges were identified in department decision making, and planning structures were identified by the UK Department for International Development (DFID) respondent and by the DODMA. Lack of resources and the inefficient use of available resources were raised by many interviewees as being the root causes of these problems.

Policy cycles and their timeframe also create barriers to the use of climate information. Policy analysis and interview data suggest that the longest timeframe for political decision making is currently over a 10-15 year horizon. The DEPD leads on this planning, but in interviews stressed that they 'don't yet use climate information for timescales of five years or more when appraising new projects or policies' as they were unaware that it existed. Sectoral planning should last for five years and align with the time period for the Malawi Growth and Development Strategy (currently in its second phase, 2011-2016). In reality, the time taken for strategies to be finalized means that they are not all operating on the same cycle. Such short planning horizons currently make it difficult to integrate medium- to long-term climate projections.

Although the DEPD is accustomed to working on medium-term timeframes, the majority of workshop participants in other sectoral departments have a shorter timeframe of up to 5 years. Thus, despite being able to identify a wishlist of future climate information needs in the role-playing activity, they had difficulty in translating this into their real-life decision making. Such findings agree with other studies in SSA, where short-term (5-year) policy cycles are prevalent and the availability of climate information is limited (Vogel, Moser, Kasperson, \& Dabelko, 2007; Ziervogel, Shale, \& Du, 2010).

The timing of the receipt of weather information (sub-annual seasonal and 5-10 day forecasts) can also be problematic. Several departments noted that the existing use of climate services tends to be reactive; they respond to information when prompted by an extreme event rather than to information provided in advance. This can mean that extremes are a surprise, leaving little time to prepare, and necessitating costly relief and rehabilitation efforts. To overcome this, a DoDMA interviewee suggested that 'early warning could be provided a week in advance and that the links between disaster risk reduction and climate change adaptation could be strengthened in government planning'.

\subsection{What weather and climate information do Malawi's ministries and departments think would be useful to inform their decision making?}

The workshop activities provided data on climate services needs across three different timescales identified from interviews with decision makers: sub-annual (daily to seasonal), short-term (1-5 years), and medium-term information (6-20 years). In investigating this, the need was stressed to not be constrained by what they believe to exist at the present time, but to consider what they would ideally need to be available to best use in their planning (regardless of the current and/or future feasibility from a science perspective) to ensure climate-resilient decisions are made. By highlighting what would be useful for decision making, this list can help to prioritize the development of, and investment in, climate services nationally and regionally. This section looks at sub-annual, short-term, and medium-term information in turn. 
Regarding sub-annual weather information, average annual rainfall totals and distribution were identified as being most important. In addition to the probabilistic seasonal forecast, more significant for all sectors was information on the nature of that rainfall - about the likely duration of the annual wet season and the potential for dry spells within this. The MoAFS stated that it would be very useful to have more frequent updates within the rainy season as well as longer-range forecasts than the current 5-10 day forecasts (for example, a 2-3 week forecast). This echoes recent case study findings (Simelton et al., 2013; Warner \& Afifi, 2013).

Sub-annual information on the occurrence of extreme events - especially floods and droughts but also strong winds and hail - was also regarded as being desirable, as was insight into the location of these extremes to enable cascading of early warning. The Environmental Affairs Department (EAD) stated that national-level maps (downscaled from global climate models) of, for instance, flood risk, were vital. Both the MoIWD and the MoAFS identified current temperature information as important, and the MoIWD also considered both sub-annual forecasts and annual projections of humidity and evaporation to be useful.

A role for multi-annual short-term information, on a 1-5 year timescale, was identified by a variety of departments. Annual rainfall totals at high resolution each year for the next five years, along with temperature, humidity and evaporation information, could be used by the MoIWD to conduct hydrological modelling at a sub-basin scale. Projected annual rainfall totals could enable projections of quantity of surface water and groundwater. Population trends and land use (cover and change) could also be factored in to investigate how water demands may change under climate change. The MoIWD proposed that the most useful weather and climate information will vary by catchment, highlighting the need for information on how climate change will interact with local conditions to influence flooding.

The MoAFS also stated that they needed data on a 1-5 year timescale, and the DoDMA raised the need for information on extreme events and the impact of climate change on agricultural productivity over the next two years. Similarly, the MLGRD argued that they needed shorter-term climate projections than the current mid-century ones to better support their three-year planning horizons.

All the departments involved in the research recognized that the short-term information needs that they identified above would also be useful on a multi-annual medium-term (6-20 years) timescale. The DEPD requested weather and climate projections for 15 years to fit in with their longer-term planning cycle. The DAES identified that information on a 5-10 year timescale would enable better planning for the agricultural sector, while the DoDMA believe that medium-longer term climate projections would support its international commitments in developing Malawi's National Adaptation Plan (NAP). The MoIWD want longer-term predictions to better plan future irrigation investments and the MoEPWD stated that the future heat/temperature range over the next 5-10 years is important as people with albinism and/or sight problems may need to be provided with special lotions and/or sunglasses.

Beyond the information needs themselves, the downstream issues of packaging and communication structures required to effectively translate information into use were also reiterated. The EAD wanted the 5 year information to be in the form of adaptation scenarios so as to support the planning of appropriate options, while the MoEPWD also considered that projections based on a range of socio-economic scenarios would enable future planning. The MoIWD's need is for a tool to facilitate decision making and to enable identification of areas where future investments in water and sanitation infrastructure are needed. 
During the consultations, NGOs and donors also noted the potential to use short- and medium-term climate information in their activities, with many interviewees stating that the DCCMS is open and willing to freely share climate information. Data from weather stations across the country have been used to trigger publicly supported index-linked weather insurance under a number of pilot schemes (Osgood et al., 2007; Osgood, Suarez, Hansen, Carriquiry, \& Mishra, 2008). However, NGOs and donors noted climate information for 5-40 years could better inform public insurance models and more clearly define trigger points for food insecurity and the longer-term framing of sustainable insurance payment schemes. There are also a number of attempts under way to improve observational records, supported by donors, government, and NGOs.

\section{Discussion: what is required to increase the use of climate information in decision making?}

In addition to addressing the challenges outlined above, more effective use of climate services planning requires greater understanding and confidence in the use of climate projections by decision makers. The workshop games showed that planners are very aware of the need to 'future-proof' decisions, but are unaware of the existence of climate projections that can enable that in a more robust manner than statistical extrapolation based on past observations. This is partly because there is insufficient capacity of decision makers to evaluate the range of projections that exist, and the varying results for projected temperature and rainfall change (Jones et al., 2014). Having one set of national projections under different socio-economic scenarios - ideally created using the latest available climate science - will improve the likelihood of inclusion in sectoral planning at the national level. Relying on the DCCMS to undertake all these roles - generating local weather and climate information, and interpreting, disseminating, and communicating projections from international sources to different sectors - is unrealistic given the number of current staff (13 in the national headquarters). There is thus a potential role for boundary organizations to bridge the gap between international producers of climate information and national users. This section outlines in turn these three key actions to increase the use of climate information in decision making.

\subsection{Capacity building of decision makers around the opportunities and limitations of climate projections}

Users of climate services are currently rooted in the notion that future circumstances can be predicted based on past patterns (cf. Rayner, Lach, \& Ingram, 2005). For instance, when presented with an annual planning decision, all groups in the role-playing activity chose a multi-year type of information (e.g. multi-year drought forecast or multi-year rainfall and temperature forecast). When asked why, the groups argued that it is important to know what has happened in the past in order to 'future-proof'. The literature shows that valuable lessons can be learned from the past (e.g. Boyd, Cornforth, Lamb, Tarhule, Lele, \& Brouder, 2013; Dixon, Stringer, \& Challinor, 2014; Hammill, Harvey, \& Echeverria, 2013). However, under climate change, looking backwards alone will not provide sufficient insight to guide robust future climate-resilient planning (Vincent et al., 2013; Wise et al., 2014). This finding indicates a lack of understanding of what a multi-year forecast is and the mechanism through which it is generated (i.e. that it is a projection of future weather and climate and not just a 
historical weather and climate pattern) (cf. Kirchhoff, Lemos, \& Engle, 2013). It also shows a lack of awareness regarding both the types of information that can be generated, and the accuracy and efficacy of past trends in predicting future weather and climate (Dessai \& Hulme, 2004).

Various departments raised the issue of limited capacity to understand weather and climate information. To effectively integrate short- to medium-term information into planning, they will need additional knowledge on the opportunities and limitations of projections, and how to deal with information on a timescale longer than a seasonal basis that takes into account changing trends (Rayner, et al., 2005). As one interviewee from the MoAFS noted, 'it's not enough to have the information but [we need] to understand how to use it'.

\subsection{Developing one set of nationally agreed scenarios}

Embracing uncertainty and the need for evidence-informed decision making is a key finding in the regional and international debate on steps needed to enhance the value and impact of climate science (Daron, 2014; Ranger, 2013; Rose, 2014; USAID, 2013; Vaughan \& Dessai, 2014). However, the 'Paying for Predictions' game with seasonal forecasts showed that dealing with the concept of uncertainty in itself does not impede the utility of information for decision makers. Instead, it is the uncertainty related to which model and projections to believe, as opposed to the inherent uncertainty of future modelling, which is problematic. Generating robust climate projections - and having one set of nationally agreed scenarios - would help to alleviate this confusion. It would also contribute to addressing another concern highlighted by several interviewees - the need to improve understanding of climate change and the risks it poses to different sectors as, without that, decision makers cannot even consider including it in their plans. Ensuring that nationally agreed climate projections are high resolution would also improve the likelihood of their use (Lemos, Kirchhoff, \& Ramprasad, 2012; Wood, Jina, Jain, Kristjanson, \& DeFries, 2014).

\subsection{Identifying boundary organizations to effectively communicate between information providers and users}

The findings from Malawi highlight that uncertainty, inherent in using climate information, can stem from inadequate understanding of the generation of weather and climate information and its opportunities and limitations. The expertise - and often interests - of the DCCMS and its personnel is in generating the information, not in interpreting or tailoring it for the varied requirements of different sectors. Instead, they disseminate it through the existing national channels to other departments, and the staff there are responsible for its interpretation. However, end-users are unable to understand the inherent uncertainty in the information and that advice resulting from it cannot be relied upon as the absolute truth. The Department of Water Supply Services in the MoIWD reiterated that 'we are cautious about giving out warnings based on modelling, not just observations'. This demonstrates that although end-users make a range of decisions under uncertainty (cf. Lemos \& Rood, 2010), a lack of understanding persists about how to interpret climate information. Findings suggest that greater attention is needed on communicating uncertainties (Pidgeon \& Fischhoff, 2011), and this applies throughout SSA. The capacity of the DCCMS to undertake all these roles without a significant increase in the numbers of appropriately trained staff is, however, an impediment. 
Boundary organizations that work at the interface between communities of experts and communities of decision makers (Cash et al., 2003) have been highlighted as an important mechanism in ensuring climate information is optimally used by decision makers in a variety of sectors elsewhere, including in water management in Brazil (Kirchhoff et al., 2013) and in coastal management in Australia (Shaw, Danese, \& Stocker, 2013). Our findings highlight the communication gap between information providers and users, and indicate that there may be a role for boundary organizations. Yet the role and effectiveness of these structures in Malawi and other countries in SSA in linking climate information with decision making is understudied. Moreover, the role of such boundary organizations depends on their legitimacy, saliency, urgency, and credibility (Sternlieb, Bixler, Huber-Stearns, \& Huayhuaca, 2013).

\section{Conclusions}

The longest current timeframe for political decision making in Malawi is over a 10-15 year time horizon. Sectoral planning processes currently take place on a short timeframe of up to 5 years. There is no evidence of departments using short-, medium- or long-term climate projections in their current decision making, despite the availability of regionally downscaled information from various sources. Instead, only sub-annual weather forecasts (from daily up to seasonal) provided by DCCMS are used. This agrees with other studies across SSA (Jones et al., 2014). Limited use of existing information represents a significant barrier to climate change adaptation (Eisenack et al., 2014; Rose, 2014).

Various challenges emerged in the use of existing climate services during the interviews and the workshop, relating to scale, accessibility and credibility, policy planning cycles, and timing. Together, these limitations currently impede the incorporation of climate and weather information into national policy planning and decision making in SSA. However, findings show that there is scope for climate information to be more appropriately interpreted, packaged, and communicated in order for users to be able to apply it so that it can deliver adaptation benefits across sectors on a national scale in SSA.

There are implications for climate scientists, and the funders of climate science, in terms of the directions for development in order to meet the needs of decision makers. Our findings highlight that there is a potentially high user demand for climate information that currently does not exist. This includes short-term multi-annual climate information that can be used in planning up to a 5 year timescale, and spatially explicit information on likely extreme events. Many departments identified a need for multiyear (up to 5 years in advance) forecasts for parameters including temperature, intensity, amount and distribution of rainfall, and drought. All departments recognized that the type of short-term information that they identified would also be useful on a 6-20 year timescale. However, investments at the national level are also needed in order to make more effective use of current scientific capacities to provide climate information at higher resolution.

There are also implications for the donor community to invest in and support the delivery of improved climate services. Initial investments need to target awareness raising and capacity building so that decision makers can first gain a better understanding of what climate information is - both currently and potentially available - and how best to interpret and use it in planning processes (Agrawala $\&$ Van Aalst, 2008). This will help decision makers to understand the utility of climate services, and would prompt a shift in national mindsets away from reliance upon past observations and linear 
modelling to use of future projections. Once government personnel are aware of what they could have in the way of projections, they then need to be shown how to use them, and how such information can be incorporated into planning processes. Without building this capacity, donors run the risk of investing in the generation of vast amounts of information that remains unused. Such support to climate services would mean assistance to the DCCMS to better communicate existing locally and internationally generated climate information, and to play a role in developing the science to meet the needs identified by decision makers.

\section{Acknowledgements}

We thank all the government and non-government staff from Malawi who participated in the various phases of this research process, and also Diana Chanika Mataya and David Mkwambisi for their support in organizing the interviews and workshop. Additional thanks go to Lindsey Jones from the Overseas Development Institute for reviewing an earlier draft. Any errors of interpretation remain our own responsibility.

\section{Disclosure statement}

No potential conflict of interest was reported by the authors.

\section{Funding}

This work was supported and funded by a National Pilot Case Study grant as part of the Department for International Development (DFID)/ Natural Environment Research Council (NERC) Future Climate for Africa programme, managed by the Climate and Development Knowledge Network.

\section{Supplemental data}

Supplemental data for this article can be accessed at http://dx.doi.org/10.1080/14693062.2015. 1075374.

\section{Note}

1. We use climate services to refer to the whole timeframe of information, from short-term weather forecasts to long-term climate projections. Although our focus was to investigate the use of climate information (projections), we also include the use of weather information (from daily to sub-annual forecasts).

\section{References}

Agrawala, S., \& Van Aalst, M. (2008). Adapting development cooperation to adapt to climate change. Climate Policy, 8, 183-193. doi:10.3763/cpol.2007.0435 
Boyatzis, R. E. (1998). Transforming qualitative information: Thematic analysis and code development. Thousand Oaks, CA: Sage.

Boyd, E., Cornforth, R. J., Lamb, P. J., Tarhule, A., Lele, M. I., \& Brouder, A. (2013). Building resilience to face recurring environmental crisis in African Sahel. Nature Climate Change, 3, 631-637. doi:10.1038/ nclimate1856

Cash, D. W., Clark, W. C., Alcock, F., Dickson, N. M., Eckley, N., Guston, D. H., . . Mitchell, R. B. (2003). Knowledge systems for sustainable development. Proceedings of the National Academy of Sciences, 100, 8086-8091. doi:10. 1073/pnas.1231332100

Conway, D., \& Mustelin, J. (2014). Strategies for improving adaptation practice in developing countries. Nature Climate Change, 4, 339-342. doi:10.1038/nclimate2199

Daron, J. (2014). Challenges in using a robust decision making approach to guide climate change adaptation in South Africa. Climatic Change, 1-15. doi:10.1007/s10584-014-1242-9

Dessai, S., \& Hulme, M. (2004). Does climate adaptation policy need probabilities? Climate Policy, 4, 107-128. doi:10.1080/14693062.2004.9685515

Dixon, J. L., Stringer, L. C., \& Challinor, A. J. (2014). Farming system evolution and adaptive capacity: Insights for adaptation support. Resources, 3, 182-214.

Eisenack, K., Moser, S. C., Hoffmann, E., Klein, R. J. T., Oberlack, C., Pechan, A., ... Termeer, C. J. A. M. (2014). Explaining and overcoming barriers to climate change adaptation. Nature Climate Change, 4, 867-872. doi:10. 1038/nclimate2350

Hammill, A., Harvey, B., \& Echeverria, D. (2013). Understanding needs, meeting demands: A user-oriented analysis of online knowledge brokering platforms for climate change and development. London: International Institute for Sustainable Development.

James, R., Washington, R., \& Rowell, D. P. (2014). African climate change uncertainty in perturbed physics ensembles: Implications of global warming to $4^{\circ} \mathrm{C}$ and beyond. Journal of Climate, 27, 4677-4692. doi:10.1175/jcli-d13-00612.1

Jones, L., Ludi, E., Beautement, P., Broener, C., \& Bachofen, C. (2013). New approaches to promoting flexible forwardlooking decision-making: Insights from complexity science, climate change adaptation and 'serious gaming'. A report for the Africa climate change resilience alliance. London: Overseas Development Institution.

Jones, L., Roux, J.-P., Scott, C., \& Tanner, T. (2014). Background briefing: Opportunities and barriers to the uptake of long-term climate information in African decision-making (Future climate for Africa/CDKN report). London: Overseas Development Institute.

Kirchhoff, C. J., Lemos, M. C., \& Engle, N. L. (2013). What influences climate information use in water management? The role of boundary organizations and governance regimes in Brazil and the U.S. Environmental Science and Policy, 26, 6-18. doi:10.1016/j.envsci.2012.07.001

Kulima Integrated Development Solutions. (2013). Report of scoping study on the potential to stimulate private sector engagement in building disaster resilience and climate change adaptation in Mozambique (Report submitted to PriceWaterhouseCoopers).

Kusangaya, S., Warburton, M. L., Archer van Garderen, E., \& Jewitt, G. P. W. (2014). Impacts of climate change on water resources in southern Africa: A review. Physics and Chemistry of the Earth, Parts A/B/C, 67-69, 47-54. doi:10. 1016/j.pce.2013.09.014

Lemos, M. C., Kirchhoff, C. J., \& Ramprasad, V. (2012). Narrowing the climate information usability gap. Nature Climate Change, 2(11), 789-794. Retrieved from http://www.nature.com/nclimate/journal/v2/n11/abs/ nclimate1614.html\#supplementary-information

Lemos, M. C., \& Rood, R. B. (2010). Climate projections and their impact on policy and practice. Wiley Interdisciplinary Reviews: Climate Change, 1, 670-682. doi:10.1002/wcc.71

Lindseth, G. (2005). Local level adaptation to climate change: Discursive strategies in the Norwegian context. Journal of Environmental Policy \& Planning, 7, 61-84. doi:10.1080/15239080500251908 
McSweeney, C., New, M., \& Lizcano, G. (2010). UNDP climate change country profiles, Malawi. UNDP. Retrieved from http://country-profiles.geog.ox.ac.uk

Mendler de Suarez, J., Suarez, P., Bachofen, C., Fortugno, N., Goentzel, J., Gonçalves, P., .. Virji, H. (2012). Games for a new climate: experiencing the complexity of future risks (Pardee Center Task Force Report). Boston, MA: The Frederick S. Pardee Center for the Study of the Longer-Range Future, Boston University.

Niang, I., Ruppel, O. C., Abdrabo, M. A., Essel, A., Lennard, C., Padgham, J., \& Urquhart, P. (2014). Africa. In V. R. Barros, C. B. Field, D. J. Dokken, M. D. Mastrandrea, K. J. Mach, T. E. Bilir, ... L. L. White (Eds.), Climate change 2014: Impacts, adaptation, and vulnerability. Part B: Regional aspects. Contribution of Working Group II to the Fifth Assessment Report of the Intergovernmental Panel on Climate Change (Chapter 22, pp. 1199-1265). Cambridge/ New York, NY: Cambridge University Press.

Osgood, D. E., McLaurin, M., Carriquiry, M., Mishra, A., Fiondella, F., Hansen, J. W., .. Ward, M. N. (2007). Designing weather insurance contracts for farmers in Malawi, Tanzania and Kenya: Final Report to the Commodity Risk Management Group (IRI Technical Report). New York, NY: International Research Institute for Climate and Society.

Osgood, D. E., Suarez, P., Hansen, J., Carriquiry, M., \& Mishra, A. (2008). Integrating seasonal forecasts and insurance for adaptation among subsistence farmers: The case of Malawi. World Bank Policy Research Working Paper Series. Retrieved from http://ssm.com/abstract=1149603

van Pelt, S. C., Haasnoot, M., Arts, B., Ludwig, F., Swart, R., \& Biesbroek, R. (2015). Communicating climate (change) uncertainties: Simulation games as boundary objects. Environmental Science and Policy, 45, 41-52. doi:10.1016/j. envsci.2014.09.004

Pidgeon, N., \& Fischhoff, B. (2011). The role of social and decision sciences in communicating uncertain climate risks. Nature Climate Change, 1, 35-41.

Ranger, N. (2013). Topic guide. Adaptation: Decision-making under uncertainty (Evidence on Demand Report). London: Department for International Development.

Rayner, S., Lach, D., \& Ingram, H. (2005). Weather forecasts are for wimps: Why water resource managers do not use climate forecasts. Climatic Change, 69, 197-227. doi:10.1007/s10584-005-3148-z

Rose, D. C. (2014). Five ways to enhance the impact of climate science. Nature Climate Change, 4, 522-524. doi:10. 1038/nclimate2270

Shaw, J., Danese, C., \& Stocker, L. (2013). Spanning the boundary between climate science and coastal communities: Opportunities and challenges. Ocean and Coastal Management, 86, 80-87. doi:10.1016/j.ocecoaman. 2012.11.008

Shongwe, M. E., van Oldenborgh, G. J., van den Hurk, B. J. J. M., de Boer, B., Coelho, C. A. S., \& van Aalst, M. K. (2009). Projected changes in mean and extreme precipitation in Africa under global warming. Part I: Southern Africa. Journal of Climate, 22, 3819-3837. doi:10.1175/2009jcli2317.1

Simelton, E., Fraser, E. D. G., Termansen, M., Benton, T. G., Gosling, S. N., South, A., . . Forster, P. (2012). The socioeconomics of food crop production and climate change vulnerability: A global scale quantitative analysis of how grain crops are sensitive to drought. Food Security, 4, 163-179. doi:10.1007/s12571-012-0173-4

Simelton, E., Quinn, C. H., Batisani, N., Dougill, A. J., Dyer, J. C., Fraser, E. D. G., ... Stringer, L. C. (2013). Is rainfall really changing? Farmers' perceptions, meteorological data, and policy implications. Climate and Development, 5 , 123-138. doi:10.1080/17565529.2012.751893

Sternlieb, F., Bixler, R. P., Huber-Stearns, H., \& Huayhuaca, C. a. (2013). A question of fit: Reflections on boundaries, organizations and social-ecological systems. Journal of Environmental Management, 130, 117-125. doi:10.1016/j. jenvman.2013.08.053

Stringer, L., Dougill, A., Dyer, J., Vincent, K., Fritzsche, F., Leventon, J., ... Kalaba, G. (2014). Advancing climate compatible development: Lessons from southern Africa. Regional Environmental Change, 14, 713-725. doi:10. 1007/s10113-013-0533-4

USAID. (2013). The value of climate services across economic and public sectors. A review of relevant literature (Technical Report). Washington, DC: United States Agency for International Development. 
Vaughan, C., \& Dessai, S. (2014). Climate services for society: origins, institutional arrangements, and design elements for an evaluation framework. Wiley Interdisciplinary Reviews: Climate Change, 5, 587-603. doi:10. $1002 /$ wcc. 290

Vincent, K., Cull, T., Chanika, D., Hamazakaza, P., Joubert, A., Macome, E., \& Mutonhodza-Davies, C. (2013). Farmers' responses to climate variability and change in southern Africa - is it coping or adaptation? Climate and Development, 5, 194-205. doi:10.1080/17565529.2013.821052

Vincent, K., Dougill, A. J., Dixon, J. L., Stringer, L. C., Cull, T., Mkwambisi, D. D., \& Chanika, D. (2014). Actual and potential weather and climate information needs for development planning in Malawi: Results of a future climate for Africa pilot case study. In Climate Development Knowledge Network (Ed.), Future climate for Africa pilot case studies. Retrieved from http://cdkn.org/resource/climate-information-decision-making-malawi/

Vincent, K., Dougill, A. J., Mkwambisi, D. D., Cull, T., Stringer, L. C., \& Chanika, D. (2014). Analysis of existing weather and climate information for Malawi (Report). Pietermaritzburg: Kulima Integrated Development Solutions.

Vogel, C., Moser, S. C., Kasperson, R. E., \& Dabelko, G. D. (2007). Linking vulnerability, adaptation, and resilience science to practice: Pathways, players, and partnerships. Global Environmental Change, 17, 349-364. doi:10.1016/ j.gloenvcha.2007.05.002

Warner, K., \& Afifi, T. (2013). Where the rain falls: Evidence from 8 countries on how vulnerable households use migration to manage the risk of rainfall variability and food insecurity. Climate and Development, 6, 1-17. doi:10.1080/17565529.2013.835707

Washington, R., James, R., Pearce, H., Pokam, W. M., \& Moufouma-Okia, W. (2013). Congo Basin rainfall climatology: Can we believe the climate models? Philosophical Transactions of the Royal Society B: Biological Sciences, 368(1625). doi:10.1098/rstb.2012.0296

Wise, R. M., Fazey, I., Stafford Smith, M., Park, S. E., Eakin, H. C., Archer Van Garderen, E. R. M., \& Campbell, B. (2014). Reconceptualising adaptation to climate change as part of pathways of change and response. Global Environmental Change. doi:10.1016/j.gloenvcha.2013.12.002

Wood, S. A., Jina, A. S., Jain, M., Kristjanson, P., \& DeFries, R. S. (2014). Smallholder farmer cropping decisions related to climate variability across multiple regions. Global Environmental Change, 25, 163-172. doi:10.1016/ j.gloenvcha.2013.12.011

Ziervogel, G., Shale, M., \& Du, M. (2010). Climate change adaptation in a developing country context: The case of urban water supply in Cape Town. Climate and Development, 2, 94-110. doi:10.3763/cdev.2010.0036 